\title{
Pesticides and Chemicals as Potential Risk Factors of Aplastic Anemia: A Case-Control Study Among a Pakistani Population
}

\author{
Muhammad Asif Syed (D) \\ Aneela Atta Ur Rahman ${ }^{2}$ \\ Muhammad Ilyas Siddiqui (iD ${ }^{2}$ \\ Ashique Ali Arain (D) ${ }^{3}$ \\ 'Department of Health, Government of \\ Sindh, Karachi, Pakistan; ${ }^{2}$ Department of \\ Community Medicine \& Public Health \\ Sciences, Liaquat University of Medical \\ and Health Sciences, Jamshoro, Pakistan; \\ ${ }^{3}$ Department of Pharmacology, \\ Muhammad Medical College, Mirprkhas, \\ Sindh, Pakistan
}

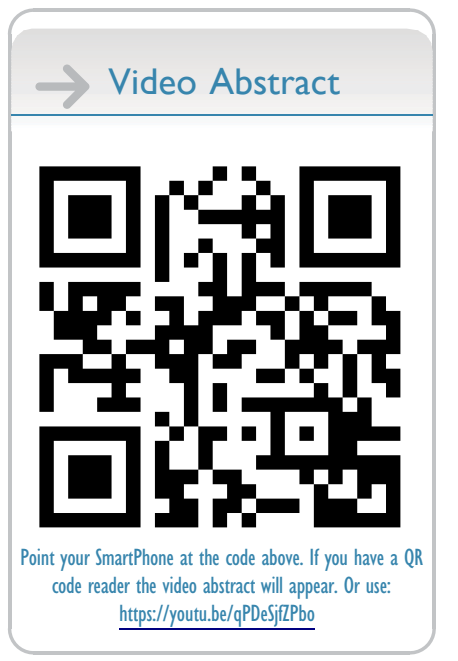

Correspondence: Ashique Ali Arain Tel +923333389250

Email Ashiquepcmd77@yahoo.com
Introduction: Aplastic anemia is a rare and potentially life-threatening hematological disorder with incidence of 1.4 to 14 cases/million. It is associated with exposures to certain environmental chemicals, drugs and infections. The objective was to investigate the association of illness with family history of aplastic anemia, exposure to pesticides and chemicals.

Methodology: A hospital-based case-control study (191 cases, 696 controls) was conducted from 1st January 2015 to 31 st December 2018 in Karachi, Sindh. Cases were patients with diagnosis of aplastic anemia confirmed with bone marrow biopsy. Controls neither had aplastic anemia nor other hematological chronic diseases. An in-person interview was conducted to collect demographic information, family history of aplastic anemia, and history of pesticide and chemical exposure. The adjusted odds ratios (aOR) with 95\% confidence intervals (CI) were estimated via SPSS v22.

Results: A total of 191 confirmed aplastic anemia cases were selected. Mean age was 29 years (range: 4-69) and predominantly there were males 129 (67.5\%). The majority, 84 $(44.0 \%)$, of the cases were aged $16-30$ years. In multivariate analysis models, the significant associations were observed between aplastic anemia with family history of aplastic anemia $(\mathrm{aOR}=13.3$, 95\% C.I 3.66-48.50), exposure to pesticides $(\mathrm{aOR}=2.1,95 \%$ C.I $1.23-3.61)$ and chemicals (aOR=3.6, 95\% C.I 2.06-6.34).

Conclusion: This study observed a significant association of aplastic anemia with family history of aplastic anemia, exposure to pesticide and insecticide exposure. However, to establish this connection, further longitudinal studies are warranted.

Keywords: aplastic anemia, exposure, pesticide, chemicals, family history

\section{Introduction}

Aplastic anemia (AA) is a life-threatening hematological illness with reduced ability to produce red blood cells, neutrophils, monocytes and platelets. It is characterized by the combination of peripheral-pancytopenia and bone-marrow hypo-cellularity. ${ }^{1}$ Certain environmental ${ }^{2}$ and host related factors begin the autoimmune reaction, ${ }^{3}$ leading to bone-marrow failure (disease development). Only one case-control study highlighted the environment risk factors for AA in Pakistan. ${ }^{4}$ There are limited studies conducted to provide evidence that environmental risk factors are associated with AA. Pesticides (organochlorine, organophosphates, carbamates and paraquat) are known risk factors for AA. ${ }^{5}$ Furthermore, chemicals (benzene and arsenic) have been found to be significantly associated with AA. ${ }^{6}$ 
Other risk factors have also been identified such as seronegative hepatitis ${ }^{7}$ and complication (extremely rare) of pregnancy. ${ }^{8}$ Other available literature is only limited to case reports/case series that mainly emphasize clinical aspects of AA. ${ }^{9,10}$ A hospital-based case-control study was therefore conducted with the objective of studying the environmental factors, ie chemicals and pesticides, and familial factors involved in AA development.

\section{Methodology}

A hospital-based case-control study was done from 1st January 2015 to 31 st December 2018 with 191 cases and 696 controls at the National Institute of Blood Borne Diseases and Bone Marrow Transplantation Center, Karachi, Sindh.

Eligible cases were selected during the routine visit of a patient (any sex or age) who had at least two decreased blood lines among three criteria defined by (1) hemoglobin $<10 \mathrm{~g} / 100 \mathrm{~mL}$, (2) granulocytes $<1.5 \times 10^{9} / \mathrm{L}$, (3) platelets $<100 \times 10^{9} / \mathrm{L}$ ) and also showed bone marrow hypocellularity on biopsy without significant fibrosis or neoplastic infiltration. Cases with radiotherapy, chemotherapy or other systemic diseases with pancytopenia such as systemic lupus erythematosus (SLE), hematological malignancy and others were excluded from the study. Cases of inherited bone marrow failure syndromes including Fanconi anemia, dyskeratosis congenita, ShwachmanDiamond syndrome and amegakaryocytic thrombocytopenia have to be excluded in all new patients based on family history and the presence of typical physical characteristics. In addition, patients with dysplastic features and cryptogenic abnormalities were not included in the research. The trained member of theNational Institute of Blood Borne Diseases and Bone Marrow Transplantation Center, Karachi, Sindh conducted the blood test.

Control participants were individuals identical to the cases in baseline characteristics such as age, sex and the hospital visited, free from AA. For each case, four controls were selected and identified according to admission diagnosis (judged to be independent of antecedent risk factors of AA). Acceptable diagnoses for inclusion were roadtraffic-accident trauma, acute abdominal emergencies, acute infections and other conditions resulting in admission for elective surgery, such as hernia repair. The exclusion criteria were the same as for cases.

A closed-ended questionnaire was used to collect information from study subjects or from parents of study participants $<15$ years old. Information on (1) socio- demographic characteristics including sex, age, ethnicity, income status, employment status and education level, (2) family history of aplastic anemia and other blood cancer, (3) history and use of pesticides (organophosphate, dichlorodiphenyltrichloroethane (DDT), mosquito repellents and insecticide) or chemicals (benzene and glycol ether) was collected.

The exposure frequency was classified into none, low and high in the case and control groups:

None: no exposure of chemicals or pesticides (any),

Low: if individual exposed to chemicals or pesticides $(<5$ years $)$,

High: if individual exposed to chemicals or pesticides ( $>5$ years).

Frequency and percentages were given for categorical variables presented in baseline characteristics. For significance of association of categorical variables (cases/controls), the chi-square test was used. Univariate and multivariate logistic regression models were run to calculate the odds ratios with $95 \%$ confidence intervals. $p$-values $\leq 0.05$ were considered as statistically significant. All analysis were done using SPSS version 22.

The study protocol was approved by the Ethical Review Committee of the Liaquat University of Medical and Health Sciences, Jamshoro. Written informed consent was obtained from each participant (parents/caregivers for minors) before interviews. All patient information was anonymized and de-identified prior to analysis by using codes and this study was conducted in accordance with the Declaration of Helsinki.

\section{Results}

A total 191 confirmed AA cases and 696 controls were selected for the study. The response rate for cases and controls was $98 \%$ and $89 \%$ respectively. The most common reason for non-response was patient's unwillingness to participate. The age at diagnosis for the AA cases ranged from 4-69 years. Median age of the participants was 27 years (cases 26 years and controls 28 years). The majority, 84 (44.0\%), of the participants belonged to the 16-30 year age group. The demographic information and socio-economic status for cases and controls are shown in Table 1.

Of the total 191 cases, 94 (49\%) had moderate type of AA, while 59 (31\%) and 38 (20\%) fulfilled the criteria for severe and very severe form of AA, respectively. Paroxysmal nocturnal hemoglobinuria (PNH) was observed in 17 (9\%) AA cases. 
Table I Demographic Information and Socio-Economic Status for Cases and Controls

\begin{tabular}{|c|c|c|}
\hline & $\begin{array}{c}\text { Cases } \\
\mathrm{N}=|9| \text { (\%) }\end{array}$ & $\begin{array}{c}\text { Controls } \\
\mathrm{N}=696 \text { (\%) }\end{array}$ \\
\hline \multicolumn{3}{|l|}{ Age Categories } \\
\hline $\mathrm{I}-15$ years & 40 (20.9\%) & $98(14.1 \%)$ \\
\hline $16-30$ years & $84(44.0 \%)$ & $308(44.3 \%)$ \\
\hline $3 \mathrm{I}-50$ years & 48 (25.1\%) & $196(28.2 \%)$ \\
\hline$>50$ years & 19 (9.9\%) & 94 (I3.5\%) \\
\hline \multicolumn{3}{|l|}{ Gender } \\
\hline Male & 129 (67.5\%) & $484(69.5 \%)$ \\
\hline Female & $62(32.4 \%)$ & $212(30.4 \%)$ \\
\hline \multicolumn{3}{|l|}{ Social Classes } \\
\hline$<10,000$ rupees & $34(38.2 \%)$ & I 44 (40.7\%) \\
\hline $10,000-20,000$ rupees & $29(32.6 \%)$ & II 6 (32.8\%) \\
\hline$>20,000$ rupees & $26(29.2 \%)$ & $94(26.6 \%)$ \\
\hline \multicolumn{3}{|l|}{ Education Level } \\
\hline No education & $80(41.9 \%)$ & $190(27.3 \%)$ \\
\hline 10-Year education & $83(43.5 \%)$ & $298(42.8 \%)$ \\
\hline 12-Year education & $14(7.3 \%)$ & $134(19.3 \%)$ \\
\hline 14 to 16 -Year education & 14 (7.3\%) & $74(10.6 \%)$ \\
\hline \multicolumn{3}{|l|}{ Family History } \\
\hline No & 161 (84.3\%) & $672(96.5 \%)$ \\
\hline Yes & $30(15.7 \%)$ & 24 (3.4\%) \\
\hline \multicolumn{3}{|l|}{ Employment Status } \\
\hline Unemployed & $104(54.5 \%)$ & 438 (62.9\%) \\
\hline Own business & $45(23.6 \%)$ & $52(7.5 \%)$ \\
\hline Job in private sector & $32(16.8 \%)$ & $150(21.6 \%)$ \\
\hline Job in public sector & 10 (5.2\%) & $56(8.0 \%)$ \\
\hline \multicolumn{3}{|l|}{ Ethnic Group } \\
\hline Sindhi & $66(34.6 \%)$ & $222(31.9 \%)$ \\
\hline Seraiki/Gujrati/Hindko & 39 (20.4\%) & $88(12.6 \%)$ \\
\hline Urdu & 30 (I5.7\%) & 132 (19.0\%) \\
\hline Punjabi & 22 (II.5\%) & $136(19.5 \%)$ \\
\hline Balochi & 22 (II.5\%) & $64(9.2 \%)$ \\
\hline Pashtu & $12(6.3 \%)$ & 54 (7.8\%) \\
\hline
\end{tabular}

The findings revealed a high proportion (15.7\%) of cases having familial predisposition of AA as compared to controls (3.4\%). On univariate analysis, significant association was found between positive family history of aplastic anemia and risk to develop aplastic anemia with odds ratio of 5.2, (95\% C.I 2.96-9.16). It means that in patients having aplastic anemia, the odds of having positive family history is 5.2 times higher as compared to controls. As per the confidence interval, we are $95 \%$ confident that the odds of positive family history is 2.96-9.16 times higher in cases of aplastic anemia as compared to controls. When the first-degree relatives were compared with the controls who had positive history of AA, the study results found statistically significant $\mathrm{OR}=4$ (95\% C.I 2.5-9.4) (Table2). The odds of having first-degree relatives is 4 times higher in cases as compared to controls. The association is precise as shown by a narrow confidence interval.

Whereas after adjusting for socio-demographic variables such as employment, ethnicity and monthly income, family history of aplastic anemia remained significantly associated with AA cases (OR=13.3, 95\% C.I 3.66-48.50). However the wide range of the confidence interval indicated that the uncertainty is greater. This might be due to the small sample size, single study setting and small duration of the study.

Table 2 Risk Estimates for Aplastic Anemia with Family History of Aplastic Anemia and Other Blood Cancer

\begin{tabular}{|l|r|r|r|r|}
\hline & Cases (\%) & Controls (\%) & OR & 95\% Lower-Upper \\
\hline \multicolumn{5}{|l|}{ Positive Family History of Aplastic Anemia } \\
\hline Yes & $30(15.7 \%)$ & $24(3.4 \%)$ & 5.2 & $2.96-9.16$ \\
No & $161(84.3 \%)$ & $672(96.5 \%)$ & & \\
\hline \multicolumn{5}{|l|}{ Aplastic Anemia Among the First-Degree Relatives } \\
\hline Yes & $21(11 \%)$ & $21(3 \%)$ & 4 & $2.5-9.4$ \\
No & $170(89 \%)$ & $675(97 \%)$ & & \\
\hline
\end{tabular}

Positive History of Other Blood Cancers Among the FirstDegree Relatives

\begin{tabular}{|r|r|r|r|r|}
\hline Yes & $10(5.2 \%)$ & $14(2 \%)$ & 3 & $1.3-8.3$ \\
No & $181(94.8 \%)$ & $682(98 \%)$ & & \\
\hline
\end{tabular}

Positive family History of AA and Risk of Moderate type of Aplastic Anemia (Case $n=94$ )*

\begin{tabular}{|l|r|r|r|r|}
\hline Yes & $10(11 \%)$ & $6(1 \%)$ & 13.6 & $4.8-38.6$ \\
No & $84(89 \%)$ & $690(99 \%)$ & & \\
\hline
\end{tabular}

Positive family Historyof AA and Risk of Severe type of Aplastic Anemia (Case $n=59$ )**

\begin{tabular}{|r|r|r|r|r|}
\hline Yes & $11(19 \%)$ & $6(1 \%)$ & 26.3 & $9.3-74.3$ \\
No & $48(81 \%)$ & $690(99 \%)$ & & \\
\hline
\end{tabular}

Positive family History of AA and Risk of Very Severe type of Aplastic Anemia (Case $\mathrm{n}=38$ )***

\begin{tabular}{|r|r|r|r|r|}
\hline Yes & $9(24 \%)$ & $6(1 \%)$ & 35.6 & $11.9-106$ \\
No & $29(76 \%)$ & $690(99 \%)$ & & \\
\hline
\end{tabular}

Notes: *Moderate AA. ** Severe AA. *** Very severe AA. 


\section{Pesticide Exposure}

Univariate analysis showed significant association of the risk of developing $\mathrm{AA}$ with the pesticide exposure $(\mathrm{OR}=3.59$, 95\% C.I 2.57-5.02) as compared to those unexposed. Analysis of the high exposed group showed that they were 3 times more at risk in developing AA than control $(\mathrm{OR}=3.4,95 \%$ C.I 2.2-5.2). The population attributable risk was calculated to be $39.8 \%$ (Table 3 ).

While adjusting confounding variables such as gender, monthly income, and ethnicity, employment, family history of aplastic anemia and chemical exposure, the association amongst pesticide exposure and development of AA remained statistically significant with $\mathrm{OR}=2.1 \quad(95 \%$ C.I 1.23-3.61). The odds of pesticide exposure is 2.1 times higher in cases as compared to controls. The association is precise.

Table 3 Risk Estimates for Aplastic Anemia with Exposure of Pesticides (Organophosphate, Dichlorodiphenyltrichloroethane (DDT), Mosquito Repellents and Insecticide)

\begin{tabular}{|c|c|c|c|c|}
\hline & Case (\%) & Control (\%) & OR & $\begin{array}{l}\text { 95\% C.I Lower- } \\
\text { Upper }\end{array}$ \\
\hline \multicolumn{5}{|c|}{ Pesticide Exposure } \\
\hline Yes & 121 (63.4\%) & $226(32.5 \%)$ & \multirow[t]{2}{*}{3.59} & \multirow[t]{2}{*}{$2.57-5.02$} \\
\hline No & $70(36.6 \%)$ & $470(67.5 \%)$ & & \\
\hline \multicolumn{5}{|c|}{$<5$ Years Exposure to PesticideS } \\
\hline Yes & 75 (39.3\%) & $|8|(26 \%)$ & \multirow[t]{2}{*}{1.8} & \multirow[t]{2}{*}{ I.3-2.5 } \\
\hline No & $116(60.7 \%)$ & $515(74 \%)$ & & \\
\hline \multicolumn{5}{|c|}{$\geq 5$ Years Exposure to Pesticides } \\
\hline Yes & $46(24 \%)$ & $59(8.5 \%)$ & \multirow[t]{2}{*}{3.4} & \multirow[t]{2}{*}{$2.2-5.2$} \\
\hline No & $145(76 \%)$ & $637(92.5 \%)$ & & \\
\hline \multicolumn{5}{|c|}{$\begin{array}{l}\text { Pesticide Exposure and Risk of Moderate type of Aplastic } \\
\text { Anemia (Case } n=94) *\end{array}$} \\
\hline Yes & $56(60 \%)$ & $226(32 \%)$ & \multirow[t]{2}{*}{3.0} & \multirow[t]{2}{*}{$1.9-4.7$} \\
\hline No & $38(40 \%)$ & $470(68 \%)$ & & \\
\hline \multicolumn{5}{|c|}{$\begin{array}{l}\text { Pesticide Exposure and Risk of Severe type of Aplastic } \\
\text { Anemia (Case } n=59)^{* *}\end{array}$} \\
\hline Yes & $44(75 \%)$ & $226(32 \%)$ & \multirow[t]{2}{*}{6.1} & \multirow[t]{2}{*}{$3.3-11.1$} \\
\hline No & $15(25 \%)$ & $470(68 \%)$ & & \\
\hline \multicolumn{5}{|c|}{$\begin{array}{l}\text { Pesticide Exposure and Risk of Very Severe type of Aplastic } \\
\text { Anemia (Case } \mathbf{n}=38 \text { )*** }\end{array}$} \\
\hline Yes & $21(55 \%)$ & $226(32 \%)$ & \multirow[t]{2}{*}{2.5} & \multirow[t]{2}{*}{$1.3-4.9$} \\
\hline No & $17(45 \%)$ & $470(68 \%)$ & & \\
\hline
\end{tabular}

Notes: *Moderate AA. ** Severe AA. ***Very severe AA.

\section{Chemical Exposure}

Development of AA with possible exposure to chemicals was also found statistically significant. The cases (29\%) that had a history of chemical exposure as compared to controls who had $17 \%$ history of exposure (Pearson chisquare $=26.30, p$-value $<0.01)$. On univariate analysis, it was revealed that the odds of occupational exposure among cases are 2.66 times higher $(\mathrm{OR}=2.66,95 \%$ C.I 1.81-3.89) as compared to controls. Duration of chemical exposure of 5 or more than 5years was highly significant with development of AA (OR=3.0, 95\% C.I 1.94-4.71) (Table 4).

After adjusting the other variables, the odds for possible chemical exposure slightly increased, ie 3.6 times higher in cases as compared to controls (95\% C.I 2.06-6.34). The association is precise.

Table 4 Risk Estimates for Aplastic Anemia with Exposure of Chemicals (Benzene and Glycol Ether)

\begin{tabular}{|c|c|c|c|c|}
\hline & Case (\%) & Control (\%) & OR & $\begin{array}{l}\text { 95\% C.I Lower- } \\
\text { Upper }\end{array}$ \\
\hline \multicolumn{5}{|c|}{ Chemical Exposure } \\
\hline Yes & 55 (28.8\%) & 92 (13.3\%) & \multirow[t]{2}{*}{2.66} & \multirow[t]{2}{*}{$1.81 \mathrm{I}-3.892$} \\
\hline No & $136(7 \mid .2 \%)$ & $604(86.8 \%)$ & & \\
\hline \multicolumn{5}{|c|}{$<5$ Year Exposure to Chemicals } \\
\hline Yes & I5 (7.8\%) & $36(5.1 \%)$ & \multirow[t]{2}{*}{1.56} & \multirow[t]{2}{*}{$0.83-2.91$} \\
\hline No & 176 (92\%) & $660(94 \%)$ & & \\
\hline \multicolumn{5}{|c|}{$\geq 5$ Years Exposure to Chemicals } \\
\hline Yes & 40 (20.9\%) & $56(8 \%)$ & \multirow[t]{2}{*}{3.0} & \multirow[t]{2}{*}{$|.94-4.7|$} \\
\hline No & I5I (79.1\%) & 640 (92\%) & & \\
\hline \multicolumn{5}{|c|}{$\begin{array}{l}\text { Chemical Exposure and Risk of Moderate type of Aplastic } \\
\text { Anemia (Case } n=94) *\end{array}$} \\
\hline Yes & $28(30 \%)$ & $92(13 \%)$ & \multirow[t]{2}{*}{2.7} & \multirow[t]{2}{*}{ I.7-4.5 } \\
\hline No & $66(70 \%)$ & $604(87 \%)$ & & \\
\hline \multicolumn{5}{|c|}{$\begin{array}{l}\text { Chemical Exposure and Risk of Severe type of Aplastic } \\
\text { Anemia (Case } n=59) * *\end{array}$} \\
\hline Yes & $21(36 \%)$ & 92 (13\%) & \multirow[t]{2}{*}{3.6} & \multirow[t]{2}{*}{$2.0-6.4$} \\
\hline No & 38 (64\%) & 604 (87\%) & & \\
\hline \multicolumn{5}{|c|}{$\begin{array}{l}\text { Chemical Exposure and Risk of Very Severe type of Aplastic } \\
\text { Anemia (Case } n=38) * * *\end{array}$} \\
\hline Yes & $6(16 \%)$ & 92 (13\%) & \multirow[t]{2}{*}{1.2} & \multirow[t]{2}{*}{$0.5-3.0$} \\
\hline No & 32 (84\%) & 604 (87\%) & & \\
\hline
\end{tabular}

Notes: *Moderate AA. ** Severe AA. ***Very severe AA. 
The above association of aplastic anemia with more than one pesticide and chemicals has several different explanations. It may be due to correlation among the different pesticides and chemicals with one or more agents which actually increases the risk of disease or it might be because of true independent effects of each agent.

\section{Discussion}

Our study showed significant association of aplastic anemia with family history of aplastic anemia, exposure to pesticide and insecticide exposure. Multivariate analysis revealed significant associations among aplastic anemia with exposure to pesticides $(\mathrm{aOR}=2.1,95 \%$ C.I $1.23-3.61)$ and chemicals ( $\mathrm{aOR}=3.6,95 \%$ C.I 2.06-6.34). The association between aplastic anemia and family history of aplastic anemia, however, was very high and significant $(\mathrm{aOR}=13.3, \mathrm{OR}=13.3,95 \%$ C.I 3.66-48.50). This wide range of confidence interval indicates that the precision is lesser and demands a higher sample size.

This study is one of the largest investigations to find out the risk factors of aplastic anemia in the association of family history of AA, pesticides and chemical exposure. Demographic variables (for cases/controls) showed the same characteristics for age, sex and social status, but differences were observed in ethnicity. Most cases and controls related from ethnic Sindhi group owing to the maximum proportion of population in Sindh Province.

In developed countries ${ }^{11,12}$ approximately two to four incident cases per million are reported every year. Asian countries had higher risk ${ }^{13,14}$ and the risk-difference is attributed to environmental exposures. ${ }^{15,16}$

We have found a male predominance in our study while according to Muir et al, ${ }^{12}$ there was no genderwise difference observed among aplastic anemia cases. This may be associated with high involvement of males in occupational endeavors as compared to females. A comparable finding was reported in a study carried out in Brazil. ${ }^{11}$

In this study, the median age of cases was 26 years (range 5-68 years). An Indian study ${ }^{17}$ showed almost similar age (27.5 years). In our findings, a predominate $44 \%$ affected age was $16-30$ years (median 23: range $16-30$ ) followed by $25 \%$ in age group $31-50$ years (median 39: range 16-30) with. An Indian study ${ }^{18}$ reported the majority of cases in the group less than 35 years which is similar to this study. The associated reason may be high involvement of this age category in occupations related to exposure of chemicals and pesticides. The current study found the highest number of cases belong to low socioeconomic status $(<10,000$ rupees/month salary); a similar finding was reported by a study ${ }^{17}$ carried out in India.

Literature review substantiates that chronic exposure of pesticide causes the progressive deterioration of bone marrow. ${ }^{11}$ This study supports and provides additional evidence for the association between aplastic anemia and pesticide exposure with odds ratio 2.2. Strength of association OR 3.4 increased with duration of exposure. On multivariate analysis, the study identified a strong association of aplastic anemia with exposure to pesticides $\left(\mathrm{aOR}=2.1\right.$, 95\% C.I 1.23-3.61). An Indian study ${ }^{19}$ performed in laboratory ${ }^{20}$ and a study published in China ${ }^{21}$ had shown comparable associations. However, a Thailand study had found no increase in AA risk for virtually all the pesticides studied. ${ }^{22}$ We reported $24 \%$ exposure of pesticides among cases which is similar to a study done in Thailand, ${ }^{6}$ while Muir et al reported $15.4 \%$ in professionals of the UK. ${ }^{12}$ Exposure of domestic pesticides was reported by $54 \%$ of the cases in the last six months $^{22}$ while no case related to domestic pesticide was identified in the current study. A possible mechanism of bone marrow failure is presence of an increased number of activated cytotoxic lymphocytes in the bone marrow and blood of AA patients. These T lymphocytes are responsible for secretion of cytokines with ability to suppress the proliferation of hematopoietic stem cells. ${ }^{3}$

In this research, we observed association of chemical exposure with aplastic anemia $(\mathrm{aOR}=3.6,95 \%$ C.I $2.06--$ 6.34). Investigation of specific types of chemical is out of the scope of the current study, but it gives a suggestion that there might be some specific types of chemicals associated with occupation. In addition, this study also identified that duration of exposure for 5 or more than 5 years with chemical increased the odds of illness. An occupation like working in a paint factory and as a painter is one of the highly reported jobs, which contains increased chance of exposure to benzene. In the line of this finding, Prihartono et al identified the association with occupational exposure to chemicals. ${ }^{6}$ Another study carried out in countries of Latin American identified association of benzene $(\mathrm{OR}=4.2,95 \%$ C.I $1.82-9.82)$ with aplastic anemia. $^{11}$

Our study reports a strong relationship of aplastic anemia with familial history of aplastic anemia $(\mathrm{aOR}=13.3$, 95\% C.I 3.66-48.50) was detected, A retrospective review of Japanese cases of aplastic anemia ${ }^{8}$ identified an excess of family consanguinity and severe anemia in the family. 
However, there was no association of genetic and hematologic familial disease or parental consanguinity with aplastic anemia in a study done in France. ${ }^{23}$ A study in $2014^{24}$ reported a family with three generations of individuals with aplastic anemia. There is a heterozygous mutation was found in the $A C D /$ TPP1 gene among these cases. These gene mutations can lead to depletion of hematopoietic stem cells and bone marrow failure. Inherited bone marrow failure syndromes and idiopathic AA share significant overlap in clinical presentation and bone marrow findings, which often poses a diagnostic challenge. ${ }^{2}$ Of the total, $113(59 \%)$ case patients' parents had a history of close blood relation with each other. In Pakistan, due to cultural norms, predominately most of the marriages are being carried out within close family members like first and second cousins. Therefore, the intra-family marriages may be the reason associated with bone marrow failure syndrome. In this regard, accurate family history of diseases is a cornerstone in the diagnosis of aplastic anemia.

\section{Conclusions and Recommendations}

This study confirmed that family history of aplastic anemia is predisposed to causation of AA. Moreover, exposure of pesticides and chemicals was also found as a risk factor of AA. The former factor is unavoidable, however the latter is preventable. Our results highlight the importance of regulations required at both community and government level to control excessive and unnecessary use of pesticides and chemicals.

\section{Study Limitations}

The current study findings may be supportive in understanding the pathophysiology of aplastic anemia in the background of environmental exposures. However, to establish this association further longitudinal studies are warranted to clarify whether one or more of these agents is responsible for this clear pattern of elevated risk.

\section{Acknowledgments}

We are grateful to the patients of aplastic anemia and controls who have participated.

\section{Disclosure}

The authors reported no conflicts of interest for this work.

\section{References}

1. Cuglievan B, DePombo A, De Angulo G. Aplastic anemia: the correct nomenclature matters. Haematologica. 2016;101(9):e391. doi:10.3324/haematol.2016.146522

2. Ly H. Genetic and environmental factors influencing human diseases with telomere dysfunction. Int J Clin Exp Med. 2009;2(2):114-130.

3. Shallis RM, Ahmad R, Zeidan AM. Aplastic anemia: etiology, molecular pathogenesis, and emerging concepts. Eur J Haematol. 2018;101(6):711-720. doi:10.1111/ejh.13153

4. Taj M, Shah T, Aslam SK, et al. Environmental determinants of aplastic anemia in Pakistan: a case-control study. J Public Health. 2016;24(5):453-460. doi:10.1007/s10389-016-0743-6

5. Jamil K, Shaik AP, Mahboob M, Krishna D. Effect of organophosphorus and organochlorine pesticides (monochrotophos, chlorpyriphos, dimethoate, and endosulfan) on human lymphocytes in-vitro. Drug Chem Toxicol. 2004;27(2):133-144. doi:10.1081/DCT-120030725

6. Prihartono N, Kriebel D, Woskie S, et al. Risk of aplastic anemia and pesticide and other chemical exposures. Asia Pac J Public Health. 2011;23(3):369-377. doi:10.1177/1010539511403605

7. Rauff B, Idrees M, Shah SAR, et al. Hepatitis associated aplastic anemia: a review. Virol J. 2011;8:87. doi:10.1186/1743-422X-8-87

8. McGowan KE, Malinowski AK, Schuh AC, Whittle W, Shehata N. Aplastic anaemia in pregnancy - a single centre, North American series. Br J Haematol. 2019;184(3):436-439. doi:10.1111/bjh.15654

9. Arewa OP, Akinola NO. Survival in primary a plastic anaemia; experience with 20 cases from a tertiary hospital in Nigeria. Afr Health Sci. 2009;9(4):290-293.

10. Akram Z, Ahmed P, Kajigaya S, et al. Epidemiological, clinical and genetic characterization of aplastic anemia patients in Pakistan. Ann Hematol. 2019;98(2):301-312. doi:10.1007/s00277-018-3542-z

11. Maluf E, Hamerschlak N, Cavalcanti AB, et al. Incidence and risk factors of aplastic anemia in Latin American countries: the LATIN case-control study. Haematologica. 2009;94(9):1220-1226. doi:10.3324/haematol.2008.002642

12. Muir KR, Chilvers CED, Harriss C, et al. The role of occupational and environmental exposures in the aetiology of acquired severe aplastic anaemia: a case control investigation. $\mathrm{Br} J$ Haematol. 2003;123(5):906-914. doi:10.1046/j.1365-2141.2003.04718.x

13. Ahmed P, Chaudhry QUN, Satti TM, et al. Epidemiology of aplastic anemia: a study of 1324 cases. Hematol Amst Neth. 2020;25(1):48-54.

14. Kojima S. Why is the incidence of aplastic anemia higher in Asia? Expert Rev Hematol. 2017;10(4):277-279. doi:10.1080/ 17474086.2017.1302797

15. Adil S, Kakepoto GN, Khurshid M, Burney IA. Epidemiological features of aplastic anaemia in Pakistan. $J$ Pak Med Assoc. 2001;51:443.

16. Dutta A, De R, Kanti T, Mitra PK, Halder A. Comparative Study of environmental factors and different addictions in aplastic anaemia patients in Eastern India. J Blood Disord Symptoms Treat. 2019;2(3):8.

17. Malhotra P, Gella V, Guru Murthy GS, Varma N, Varma S. High incidence of aplastic anemia is linked with lower socioeconomic status of Indian population. J Public Health. 2016;38(2):223-228. doi:10.1093/pubmed/fdv027

18. Mahapatra M, Singh PK, Agarwal M, et al. Epidemiology, clinico-haematological profile and management of aplastic anaemia: AIIMS experience. J Assoc Physicians India. 2015;63(3 Suppl):30-35.

19. Ahamed M, Anand M, Kumar A, Siddiqui MKJ. Childhood aplastic anaemia in Lucknow, India: incidence, organochlorines in the blood and review of case reports following exposure to pesticides. Clin Biochem. 2006;39(7):762-766. doi:10.1016/j.clinbiochem.2006.03.021

20. Chatterjee S, Basak P, Chaklader M, et al. Pesticide induced alterations in marrow physiology and depletion of stem and stromal progenitor population: an experimental model to study the toxic effects of pesticide. Environ Toxicol. 2014;29(1):84-97. doi:10.1002/ tox. 20775 
21. Wu L-Q, Shen -Y-Y, Zhang Y, et al. Multiple risks analysis for aplastic anemia in Zhejiang, China: a case-control study. Medicine (Baltimore). 2019;98(8):e14519. doi:10.1097/MD.0000000000014519

22. Kaufman DW, Issaragrisil S, Anderson T, et al. Use of household pesticides and the risk of aplastic anaemia in Thailand. The Aplastic Anemia Study Group. Int $J$ Epidemiol. 1997;26(3):643-650. doi:10.1093/ije/26.3.643

23. Baumelou E, Guiguet M, Mary JY. Epidemiology of aplastic anemia in France: a case-control study. I. Medical history and medication use. The French Cooperative Group for Epidemiological Study of Aplastic Anemia. Blood. 1993;81(6):1471-1478. doi:10.1182/blood. V81.6.1471.1471
24. Guo Y, Kartawinata M, Li J, et al. Inherited bone marrow failure associated with germline mutation of $\mathrm{ACD}$, the gene encoding telomere protein TPP1. Blood. 2014;124(18):2767-2774. doi:10.1182/ blood-2014-08-596445

\section{Publish your work in this journal}

Clinical Epidemiology is an international, peer-reviewed, open access, online journal focusing on disease and drug epidemiology, identification of risk factors and screening procedures to develop optimal preventative initiatives and programs. Specific topics include: diagnosis, prognosis, treatment, screening, prevention, risk factor modification,

Submit your manuscript here: https://www.dovepress.com/clinical-epidemiology-journal systematic reviews, risk \& safety of medical interventions, epidemiology \& biostatistical methods, and evaluation of guidelines, translational medicine, health policies \& economic evaluations. The manuscript management system is completely online and includes a very quick and fair peer-review system, which is all easy to use. 